\title{
Fototerapia Pós-Mastectomia: uma Revisão Sistemática
}

https://doi.org/10.32635/2176-9745.RBC.2019v65n1.347

\author{
Post-Mastectomy Phototherapy: a Systematic Review \\ Fototerapia Post-Mastectomía: una Revisión Sistemática
}

\author{
Alessandra de Jesus Mota Rocha'; Giovana Bergheme Franciscon De Lemos²; Rachel Trinchão Schneiberg Kalid Ribeiro
}

Resumo

Introduçáo: $\mathrm{O}$ câncer de mama, patologia mais comum entre as mulheres, promove lesão nas estruturas das células ductais e lobulares da mama, assim como no tecido mamário adjacente e sistema linfático. A mastectomia é o procedimento padrão para a retirada do nódulo maligno e áreas acometidas, no qual a cirurgia desenvolve complicações físicas e funcionais. A fototerapia é um dos recursos fisioterapêuticos utilizados para minimizar os problemas ocasionados, oferecendo uma melhora na qualidade de vida das mulheres mastectomizadas. Objetivo: Descrever os possíveis efeitos da fototerapia nas complicaçóes físicas pós-mastectomia. Método: Realizou-se uma revisão sistemática nas bases de dados PubMed, LILACS, PEDro, SciELO, Bandolier, EBSCO, Clinical Evidence, MEDLINE e Biblioteca Cochrane no período de 2008 a 2018. Resultados: Dos 87 artigos encontrados, apenas seis preencheram os critérios de inclusão, nota superior de 5/10 na Escala PEDro, sendo detalhados nesta revisão. A fototerapia promoveu diminuição da dor em ombro, diminuição do volume e circunferência do linfedema no membro superior, regulação do sistema linfático e imunológico. Conclusáo: Conclui-se que a fototerapia aplicada nas complicaçóes pós-mastectomia mostrou ser uma terapêutica segura em pacientes oncológicos, sugerindo melhora sobre os aspectos da funcionalidade do indivíduo e sua qualidade de vida.

Palavras-chave: Neoplasias da Mama; Mastectomia; Fototerapia.

\begin{abstract}
Introduction: The breast cancer, a common pathology among women, promotes lesion in the ductal and lobular cell structures of the breast, as well as in the adjacent mammary tissue and lymphatic system. Mastectomy is the standard procedure for removal of the malignant nodule and areas where the surgery develops physical and functional complications. Phototherapy is one of the physiotherapeutic resources used to minimize the problems caused, offering an improvement in the quality of life of mastectomized women. Objective: To describe the effects of phototherapy on physical complications after mastectomy. Method: We performed a systematic review of the PubMed, LILACS, PEDro, SciELO, Bandolier, EBSCO, Clinical Evidence, MEDLINE and Cochrane Library databases from 2008 to 2018. Results: Of the 87 articles found, only six met the inclusion criteria, 5/10 higher grade in the PEDro Scale, being detailed in this review. Phototherapy promoted reduction of shoulder pain, decreased volume and circumference of lymphedema in the upper limb, regulation of the lymphatic and immune systems. Conclusion: It is concluded that the phototherapy applied in post-mastectomy complications has been shown to be a safe therapy in oncology patients, suggesting an improvement on aspects of the individual's functionality and quality of life.

Key words: Breast Neoplasms; Mastectomy; Phototherapy.
\end{abstract}

Resumen

Introducción: El cáncer de mama, patología más común entre las mujeres, promueve lesión en las estructuras de las células ductal y lobulares de la mama, así como en el tejido mamario adyacente y el sistema linfático. La mastectomía es el procedimiento estándar para la retirada del nódulo maligno y las áreas afectadas, donde la cirugía desarrolla complicaciones físicas y funcionales. La fototerapia es uno de los recursos fisioterapéuticos utilizados para minimizar los problemas ocasionados, ofreciendo una mejora en la calidad de vida de las mujeres mastectomizadas. Objetivo: Describir los efectos de la fototerapia en las complicaciones físicas postmastectomía. Método: Se realizó una revisión sistemática en las bases de datos PubMed, LILACS, PEDro, SciELO, Bandolier, EBSCO, Clinical Evidence, MEDLINE y Biblioteca Cochrane en el período de 2008 a 2018. Resultados: De los 87 artículos encontrados sólo seis cumplieron los criterios de inclusión, nota superior de 5/10 en la Escala PEDRO, siendo detallados en esta revisión. La fototerapia promovió disminución del dolor en el hombro, disminución del volumen y circunferencia del linfedema en el miembro superior, regulación del sistema linfático e inmunológico. Conclusión: Se concluye que la fototerapia aplicada en las complicaciones post-mastectomía mostró ser una terapéutica segura en pacientes oncológicos, sugiriendo mejora sobre los aspectos de la funcionalidad del individuo y su calidad de vida.

Palabras clave: Neoplasias de la Mama; Mastectomía; Fototerapia.

${ }^{1}$ Centro Universitário UniRuy Wyden. Salvador (BA), Brasil. Orcid iD: https://orcid.org/0000-0001-8820-8292

${ }^{2}$ Universidade Federal da Bahia (UFBA). Escola Bahiana de Medicina e Saúde Pública (EBMSP). Salvador (BA), Brasil. Orcid iD: https://orcid.org/0000-0002-3324-7283

${ }^{3}$ Centro Universitário UniRuy Wyden. EBMSP. Salvador (BA), Brasil. Orcid iD: https://orcid.org/0000-0002-0555-8623

Endereço para correspondência: Alessandra de Jesus Mota Rocha. Vila Dois Irmãos, 580 - Estrada das Barreiras. Salvador (BA), Brasil. CEP $41195-080$.

E-mail: alessandramrocha3@gmail.com 


\section{INTRODUÇÃO}

O câncer ocorre em virtude da proliferação desordenada de células neoplásicas que acomete os tecidos e órgáos. Segundo o Instituto Nacional de Câncer José Alencar Gomes da Silva (INCA) ${ }^{1}$, são esperados, para o Brasil, 59.700 casos novos de câncer de mama, para cada ano do biênio 2018-2019, e cerca de 56,33 casos para cada 100 mil mulheres. Mais frequente entre as mulheres, o câncer de mama pode ocorrer em estruturas das células dos ductos, lóbulos, tecido mamário e sistema linfático.

Durante o decurso da carcinogênese, são produzidas diversas alteraçóes fisiopatológicas, com a ruptura dos mecanismos de regulação da multiplicação celular, reparação dos genes, ativação dos proto-oncogenese, modificaçóes celulares que levam à instabilidade genômica e mutaçóes genéticas. A descoberta do câncer traz consigo diversas repercussóes na vida social, financeira, sexual e espiritual das mulheres. O profissional de saúde deve contribuir não só no tratamento ao qual se propóe, controlando as sintomatologias que afetam e limitam as pacientes, mas também restabelecer a sua qualidade de vida.

Dependendo do estadiamento clínico de cada paciente, é sugerida a mastectomia. Esse procedimento cirúrgico visa à retirada total da glândula mamária associada ou não à linfadenectomia axilar. Quando unidas, a mastectomia e a linfadenectomia aumentam a possibilidade do surgimento de complicaçóes, como por exemplo: dor, linfedema, seroma, deiscência cicatricial e diminuição de amplitudes de movimento em membros superiores, impactando negativamente na funcionalidade do indivíduo ${ }^{2-5}$.

Durante todo ciclo e fases do tratamento, torna-se essencial a presença de uma equipe multiprofissional, da qual o fisioterapeuta também faz parte e atua desde a prevenção até a reabilitação das disfunções cinético funcionais que acometem essas mulheres. Entre as condutas fisioterapêuticas para tratar as disfunçôes provenientes da mastectomia, está a fototerapia, que consiste na utilização da luz para fins terapêuticos. Cromóforos presentes na pele captam o estímulo luminoso e desencadeiam a fotobiomodulação no interior celular, a fim de promover efeito analgésico, antiedematoso, anti-inflamatório e cicatrizante ${ }^{6,7}$.

A fototerapia é aplicada por meio de equipamentos como o Light Amplification by Stimulated Emission of Radiation (laser) e o Light Emitter Diode (LED), que apresentam diversos comprimentos de onda e potências que variam da baixa à alta. A fototerapia aplicada por fisioterapeutas é a de baixa potência, com a vantagem de ser um procedimento não invasivo e promover mínimos efeitos colaterais ${ }^{8}$.

A literatura, apesar de descrever alguns efeitos da fototerapia, não é clara, havendo controvérsias quanto à aplicabilidade e aos parâmetros, ainda mais em pacientes pós-mastectomia. Diante do exposto, o objetivo deste estudo é descrever os possíveis efeitos da fototerapia aplicada em pacientes mastectomizadas, como também revisar os parâmetros utilizados nas complicaçóes decorrentes dessa cirurgia.

\section{MÉTODO}

Trata-se de uma revisão sistemática, cuja busca e avaliaçáo dos artigos foi realizada no período de dezembro de 2017 a março de 2018. Visando a um maior alcance de informaçôes, foram escolhidas as bases de dados: PubMed, LILACS, PEDro, SciELO, Bandolier, EBSCO, Clinical Evidence, MEDLINE e Biblioteca Cochrane. Foram incluídos artigos originais localizados na integra, do tipo ensaio clínico randomizado, publicados no período de 2008 a 2018, nos idiomas em inglês, espanhol e português, que abordassem a fototerapia nas complicações pós-mastectomia em mulheres.

Foram utilizados para busca os Descritores em Ciências da Saúde (DeCS): Breast Neoplasms, Phototherapy e Mastectomy, com as seguintes combinações: Breast Neoplasms AND Mastectomy AND Phototherapy, Phototherapy AND Breast Neoplasm, Breast Cancer AND Phototherapy. Foram excluídos artigos cuja abordagem da fototerapia fosse em pacientes submetidos à cirurgia conservadora de mama e nota inferior $5 / 10$ na escala PEDro.

A escala PEDro é uma ferramenta de avaliação qualitativa de ensaios clínicos controlados que permite conhecer detalhadamente como foram elaborados os ensaios clínicos, pontuá-los, e se foram respeitados os critérios éticos envolvidos na pesquisa. Os artigos foram avaliados por dois revisores independentes, os quais utilizaram a escala PEDro com ponto de corte $5 / 10$, caso não houvesse concordância entre ambas as partes, haveria um terceiro avaliador. As informaçóes pertinentes do material encontrado foram tabuladas e posteriormente discutidas.

\section{RESULTADOS}

Ao realizar a busca nas bases de dados, foi encontrado um total de 87 artigos. A primeira avaliaçáo foi por intermédio da leitura dos títulos e resumos, sendo excluídos 78 , restando para a leitura na integra apenas nove, representados na Figura 1.

Para avaliação qualitativa, utilizou-se a escala PEDro com ponto de corte $5 / 10$, na qual foram selecionados seis artigos para o estudo e excluídos três em razão de a pontuação ter sido inferior ao ponto de corte e pela falta de clareza na metodologia aplicada nos ensaios clínicos.

A amostra total de todos os artigos encontrados foi composta de 189 mulheres mastectomizadas, tratadas predominantemente pelo laser e pelo LED infravermelho, 


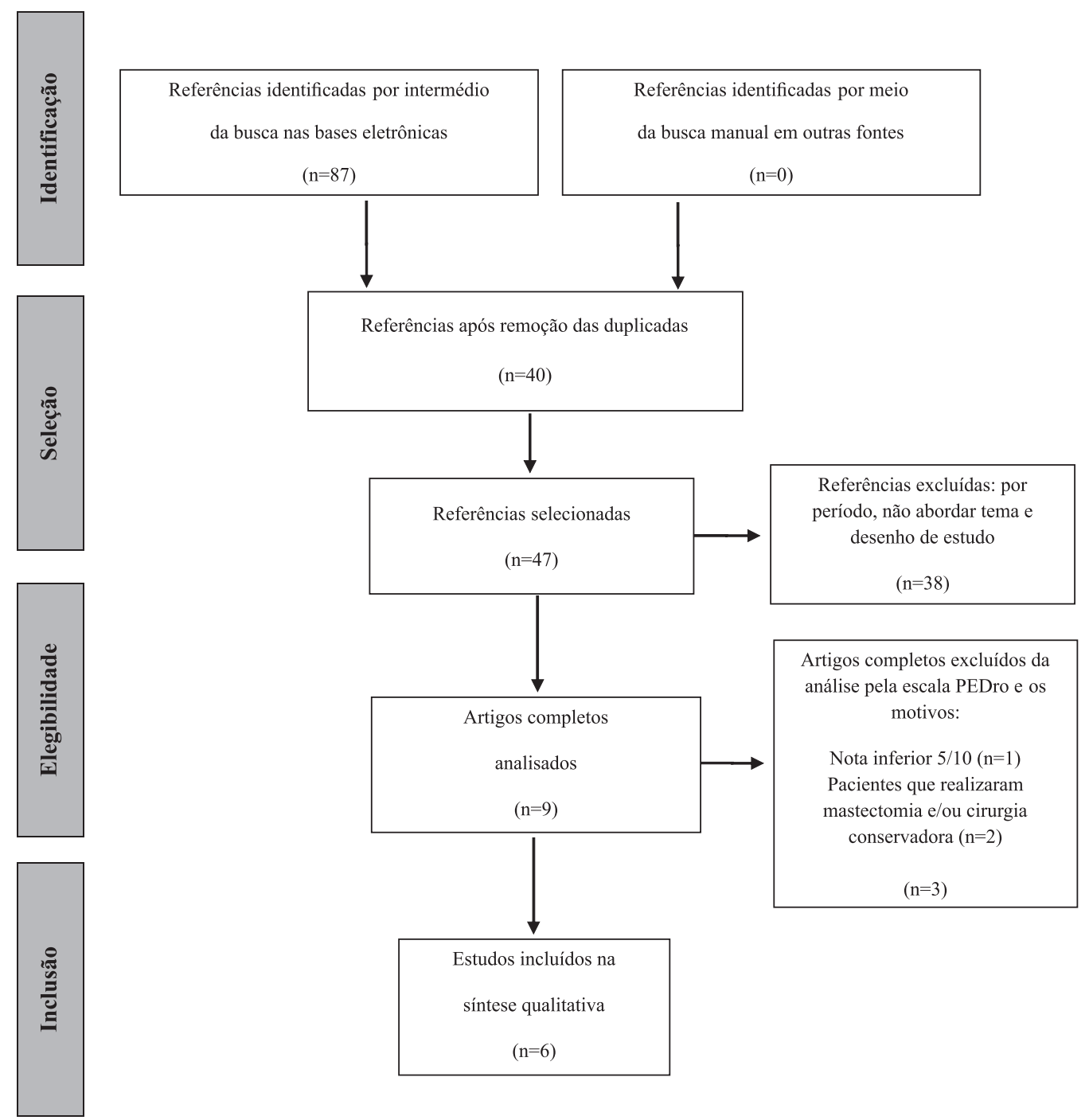

Figura 1. Fluxograma mostrando o processo de seleção dos estudos

com uma média de 56 atendimentos. Nos protocolos de tratamento com a aplicação unicamente do laser, o linfedema foi a principal complicação relatada, seguido por dor, redução de mobilidade e força de preensão palmar.

Referente aos protocolos aplicados para linfedema e analgesia, empregaram uma associação de comprimentos de ondas do laser de $905 \mathrm{~nm}$ e $808 \mathrm{~nm}$ com uma dosagem de dois joules por $\mathrm{cm}^{2}\left(\mathrm{~J} / \mathrm{cm}^{2}\right)$ cada um; para mobilidade e força de preensão palmar, adotaram um comprimento de onda de $904 \mathrm{~nm}$ e dose de 1,5 joules. Os pacientes que foram submetidos a esses ensaios clínicos obtiveram redução do volume do braço acometido pelo linfedema, com a melhora do fluxo linfático e da função da pele, apresentando, consequentemente, menos quadros álgicos.

Ao serem abordadas a mobilidade do ombro e a força de preensão palmar, colaborou-se para que as funçôes teciduais tivessem seu equilíbrio e congruência articular restabelecidos. Assim, a função dos membros superiores aos poucos foi estabelecida pelas açôes do laser já conhecidas como sua capacidade de atuar em processos inflamatórios e cicatriciais.

Já a aplicação do $L E D$ se fez presente no tratamento das alteraçóes imunológicas e cicatriciais oriundas da mastectomia, com parâmetros que variaram de 480-3.400 $\mathrm{nm}$ com a dosagem de $12 \mathrm{~J} / \mathrm{cm}^{2}$, e verificou-se que a atuação do $L E D$ no organismo influencia na capacidade do sistema imunológico em se defender do agente agressor, ativando linfócitos e células natural Killer, e as células expostas ao $L E D$ náo apresentaram capacidade de multiplicação desordenada, que é característica de células cancerosas, muito menos reaçáo adversa.

Quanto a fatores cicatriciais e inflamatórios, o LED ativa células pró-inflamatórias, fazendo com que a janela de tempo do processo inflamatório cesse mais rápido, contribuindo para a deposição de colágeno e elastina no local afetado.

As informaçôes sobre os estudos selecionados estão contidas no Quadro 1. 
Quadro 1. Estudos encontrados demostrando a aplicação da fototerapia, seus desfechos e parâmetros utilizados em pacientes mastectomizadas

\begin{tabular}{|c|c|c|c|c|c|}
\hline Autor, ano & $\begin{array}{l}\text { Desenho } \\
\text { de estudo }\end{array}$ & $\begin{array}{l}\text { Escala } \\
\text { PEDro }\end{array}$ & Complicações & $\begin{array}{l}\text { Intervenção/ } \\
\text { parâmetros }\end{array}$ & Desfechos \\
\hline $\begin{array}{l}\text { Li et al., } \\
2017\end{array}$ & $\begin{array}{l}\text { Ensaio } \\
\text { clínico }\end{array}$ & $7 / 10$ & Linfedema & $\begin{array}{l}\text { Amostra: } 63 \text { mulheres } \\
\text { GI: } 32 \\
\text { Comprimento de onda } \\
\text { entre } 6,0 \text { e } 14,0 \mu \mathrm{m}, \\
\text { duração de } 1 \text { hora por } \\
\text { dia durante } 4 \text { semanas } \\
\text { (20 dias no total) a uma } \\
\text { temperatura de } 42^{\circ} \mathrm{C} \\
\text { GB: } 31 \\
\text { Aplicação da bandagem } \\
\text { de compressão por } 12 \\
\text { horas por dia }\end{array}$ & $\begin{array}{l}\text { O infravermelho não } \\
\text { influenciou o estado apoptótico } \\
\text { das linhagens celulares MCF-7 } \\
\text { e MDA-MB231, a viabilidade } \\
\text { celular e a proliferação } \\
\text { celular, sem apresentar reação } \\
\text { adversa. Sugere-se que o } \\
\text { infravermelho seja um método } \\
\text { eficaz para linfedema, o que } \\
\text { provavelmente não induzirá } \\
\text { recorrência tumoral ou } \\
\text { metástases }\end{array}$ \\
\hline $\begin{array}{l}\text { Zhevago et } \\
\text { al., } 2017\end{array}$ & $\begin{array}{l}\text { Ensaio } \\
\text { clínico }\end{array}$ & $7 / 10$ & $\begin{array}{c}\text { Alterações } \\
\text { imunológicas }\end{array}$ & $\begin{array}{l}\text { Amostra: } 19 \text { pacientes } \\
\text { GI: } 11 \\
\text { Irradiação da área } \\
\text { lombossacra, } 15 \mathrm{~cm} \text { de } \\
\text { diâmetro de } 480-3.400 \\
\text { nm, nível de polarização } \\
95 \% \text {, duração de } 10 \\
\text { minutos e } 7 \text { sessões } \\
\text { diárias } \\
\text { GC: } 8\end{array}$ & $\begin{array}{l}\text { Após a mastectomia com } \\
\text { utilização do infravermelho, os } \\
\text { valores de monócitos aumentaram } \\
\text { e voltaram ao valores iniciais } \\
\text { pré-operatórios, o que impediu a } \\
\text { diminuição de linfócitos, estimulou } \\
\text { produção da célula natural } \\
\text { Killer e promoveu correção de } \\
\text { muitos parâmetros imunológicos } \\
\text { alterados após a cirurgia }\end{array}$ \\
\hline $\begin{array}{l}\text { Zhevago et } \\
\text { al., } 2012\end{array}$ & $\begin{array}{l}\text { Ensaio } \\
\text { clínico }\end{array}$ & $8 / 10$ & $\begin{array}{l}\text { Alterações } \\
\text { imunológicas }\end{array}$ & $\begin{array}{l}\text { Amostra: } 19 \text { pacientes } \\
\text { GI: } 11 \\
\text { Irradiação na região } \\
\text { lombossacra do } 1 \text { ao } 7 \\
\text { dia após a cirurgia, } 480 \text { - } \\
3.400 \mathrm{~nm}, 40 \mathrm{~mW} / \mathrm{cm}^{2} \text {, } \\
95 \% \text { de polarização, com } \\
\text { o diâmetro do ponto de } \\
\text { luz de } 15 \mathrm{~cm} \\
\text { GC: } 8\end{array}$ & $\begin{array}{l}\text { O infravermelho foi capaz de } \\
\text { impedir a diminuição pós- } \\
\text {-operatória nas contagens de } \\
\text { monócitos e células natural } \\
\text { Killer, a quantidade total de } \\
\text { linfócitos T e níveis de lgA; } \\
\text { promoveu a normalização mais } \\
\text { rápida da leucocitose e não } \\
\text { causou recidiva do câncer }\end{array}$ \\
\hline $\begin{array}{l}\text { Ahmed } \\
\text { Omar; } \\
\text { Abd-El-Gayed } \\
\text { Ebid; El } \\
\text { Morsy et al., } \\
2011\end{array}$ & $\begin{array}{l}\text { Ensaio } \\
\text { clínico }\end{array}$ & $8 / 10$ & Linfedema & $\begin{array}{l}\text { Amotra: } 50 \text { pacientes } \\
\text { GL: } 25 \\
\text { Comprimento de onda } \\
\text { de } 904 \text { nm sobre o axilar } \\
\text { e áreas do braço, } 3 \text { vezes } \\
\text { por semana durante } 12 \\
\text { semanas, dose de } 1,5 \mathrm{~J} / \\
\mathrm{cm}^{2}, 20 \text { minutos } \\
\text { GC: } 25\end{array}$ & $\begin{array}{l}\text { O laser melhorou após ás } 8 \\
\text { e } 12 \text { semanas a mobilidade } \\
\text { do ombro para flexão e a } \\
\text { abdução reduziu totalmente } \\
\text { a circunferência do membro e } \\
\text { aumentou a força de preensão }\end{array}$ \\
\hline $\begin{array}{l}\text { Zimin; } \\
\text { Samoilova; } \\
\text { Zhevago, } \\
2010\end{array}$ & $\begin{array}{l}\text { Ensaio } \\
\text { clínico }\end{array}$ & $6 / 10$ & $\begin{array}{l}\text { Alterações } \\
\text { imunológicas } \\
\text { e cicatriciais }\end{array}$ & $\begin{array}{l}\text { Amostra: } 17 \text { pacientes } \\
\text { Gl: } 10 \\
\text { Comprimento de onda } \\
480-3400 \mathrm{~nm}, 95 \% \text { de } \\
\text { polarização, } 40 \mathrm{~mW} / \\
\mathrm{cm}^{2}, \text { por } 10 \text { minutos com } \\
\text { diâmetro de } 15 \mathrm{~cm} \\
\text { GC: } 7\end{array}$ & $\begin{array}{l}\text { O infravermelho produziu } \\
\text { a diminuição da atividade } \\
\text { proliferativa de algumas } \\
\text { células tumorais e estimulou } \\
\text { a produção da célula natural } \\
\text { Killer }\end{array}$ \\
\hline $\begin{array}{l}\text { Lau; } \\
\text { Cheing, } \\
2009\end{array}$ & $\begin{array}{l}\text { Ensaio } \\
\text { clínico }\end{array}$ & $7 / 10$ & Linfedema & $\begin{array}{l}\text { Amostra: } 21 \text { pacientes } \\
\text { GL: } 11 \\
\text { Comprimento de onda: } \\
905 \mathrm{~nm}, 2 \mathrm{~J} / \mathrm{cm}^{2}, 3 \text { vezes } \\
\text { por semana, por } 20 \\
\text { minutos em varredura } \\
\text { GC: } 10\end{array}$ & $\begin{array}{l}\text { O laser diminuiu o volume do } \\
\text { braço, dor e incapacidade em } \\
\text { atividades da vida diária; os } \\
\text { efeitos terapêuticos mostraram } \\
\text { melhorias após cessação do } \\
\text { tratamento e escores DASH, } \\
\text { além do fluxo sanguíneo, } \\
\text { restauração do sistema de } \\
\text { drenagem e formação do tecido } \\
\text { cicatricial }\end{array}$ \\
\hline
\end{tabular}

Legendas: GB: Grupo bandagem; GC: Grupo controle; GI: Grupo intervençăo; GL: Grupo laser; J/cm²: Joules por centímetro ao quadrado; Hz: hertz; mW: miliwatt; nm: nanômetro; $\mu$ m: 1 milionésimo de metro. 


\section{DISCUSSÃO}

De acordo com os artigos revisados, a aplicação da fototerapia em pacientes mastectomizadas foi realizada por meio do laser terapêutico e do infravermelho, sendo este último citado na maioria das pesquisas encontradas. A análise bibliográfica revelou que a fototerapia diminui as principais complicaçóes pós-mastectomia como a limitação de mobilidade do ombro, linfedema e dor.

Li et al. ${ }^{9}$ avaliaram o efeito do infravermelho no linfedema de 32 pacientes mastectomizadas e compararam dados laboratoriais anteriores e posteriores à mastectomia. $\mathrm{O}$ infravermelho foi aplicado com comprimento de onda entre 6,0 e $14,0 \mu \mathrm{m}$ e o resultado foi a promoção da ativação de células de Langerhans, macrófagos e células endoteliais, com o restabelecimento da função imunológica e do sistema linfático, em pacientes que apresentaram linfedema.

Corroborando os resultados expostos anteriormente, da ação do infravermelho sobre o sistema imunológico, estudos apontam que a fototerapia por infravermelho estimula as células de defesa do organismo, como a célula natural Killer, monócitos e linfócitos T após a mastectomia. Há uma inibição do ciclo inflamatório e, mesmo com a estimulaçáo celular e a produçáo no aumento de temperatura em tecidos superficiais, o infravermelho náo foi capaz de alterar a capacidade de proliferação, viabilidade e estado apoptótico das células cancerígenas $^{10-12}$.

O infravermelho também foi aplicado com bons resultados em estudo com 19 pacientes, que revelou síntese de radicais livres disponibilizados na circulação sanguínea, permitindo assim a regeneração tecidual, com a deposiçáo de colágeno no local da cicatrização, evitando eventuais complicaçóes pós-operatórias como, por exemplo, a deiscência cicatricial, que gera dor e restrição de mobilidade do ombro ${ }^{6}$. Neste estudo, o comprimento de onda utilizado foi de 480-3400 nm, apresentando uma faixa de comprimento de onda amplo; enquanto, no artigo de Study e Emitting ${ }^{13}$, o comprimento de onda foi apenas de $540 \mathrm{nn}$ por 30 minutos.

A fototerapia pelo uso do laser foi aplicada por Lau e Cheing ${ }^{14}$ em 11 pacientes mastectomizadas com dor e linfedema no membro superior, e no grupo controle sem intervenção. O comprimento de onda utilizado foi de $905 \mathrm{~nm}$, três vezes por semana; o laser mostrou-se eficaz na diminuição do quadro álgico e do linfedema até mesmo depois da suspensão do tratamento na quarta semana nesse grupo, o que sugere a permanência da sua eficácia em longo prazo. O estudo demonstra que um dos benefícios do laser está na capacidade de aceleração do reparo tecidual, observada pela normalização mais precoce dos aspectos da pele e da restauração da função do sistema linfático em virtude da linfangiogênese, resultados também encontrados em outro estudo ${ }^{15}$.

Resultados similares foram encontrados no estudo de Ahmed Omar ${ }^{16}$. O laser com comprimento de onda semelhante, de $904 \mathrm{~nm}$, dosagem $1,5 \mathrm{~J} / \mathrm{cm}^{2}$, foi aplicado em uma amostra de 25 pacientes; no grupo controle, o laser estava desativado no momento de sua aplicação. O grupo intervenção também obteve melhora no linfedema pela diminuição da circunferência dos membros superiores, da mobilidade e da amplitude de movimento da região do ombro, como da força de preensão palmar.

Mais recentemente, Storz et al. ${ }^{17}$ utilizaram o laser com comprimento de onda $980 \mathrm{~nm}$ e dosagem 4,8 J/ $\mathrm{cm}^{2}$, parâmetros maiores que os utilizados em protocolos anteriores, entretanto, obtiveram-se resultados semelhantes da ação do laser em pacientes mastectomizadas. Mesmo com parâmetros diferentes em seus protocolos de estudo, há um consenso em ambos os artigos sobre a eficácia da aplicaçấo do laser para o tratamento de dor e linfedema.

Lau e Cheing ${ }^{14}$, em uma amostra com 11 pacientes, verificaram o laser com comprimento de onda $905 \mathrm{~nm}$, dosagem $2,0 \mathrm{~J} / \mathrm{cm}^{2}$ com duraçáo de 20 minutos, cuja funcionalidade foi avaliada por intermédio da escala DASH, e observaram que o tratamento com laser promoveu melhora na funcionalidade, na qualidade de vida e acelerou o retorno às atividades de vida diária. Validaram que, quanto mais precoce fora a recuperaçáo no pós-operatório, com a diminuição de suas complicações, melhor será o prognóstico, propiciando a inserção dessas pacientes ao convívio familiar e social.

Alguns estudos apresentaram como limitação a reduçáo no número de participantes associada a um curto período na realização dos protocolos, podendo alcançar maiores evidências em próximas pesquisas sobre os efeitos da fototerapia em um grupo mais amplo de participantes e com prolongamento do período de protocolo no qual serão submetidos. Outra limitação foi o não cegamento em artigos de terapeutas que aplicavam o laser ou LED, por terem conhecimento prévio do funcionamento dos equipamentos, podendo servir de viés aos resultados obtidos.

Apesar de existirem inúmeras publicações que abordem a fisioterapia no pós-operatório de mastectomia, poucos são os artigos com boa base metodológica, e mais escassos ainda aqueles do tipo ensaio clínico randomizado que abordem a aplicação da fototerapia em pacientes pós-mastectomia. Talvez, essa dificuldade seja explicada em virtude da complexidade que envolve questóes éticas em pesquisa, por se tratar de estudos com aplicaçáo de recursos fotoelétricos em pacientes oncológicos, e pelo desconhecimento da atuaçáo da fototerapia. 
A fotobiomodulação, quando se refere à área da oncologia, ainda é vista por alguns autores e profissionais de saúde com certo receio. Por falta de conhecimento sobre esse assunto, sentem-se inseguros por estarem estimulando a recorrência do câncer tanto em seu local de origem ou até mesmo promover metástases, por isso, há ainda pouca adesão dessa conduta.

\section{CONCLUSÃO}

Conclui-se que a fototerapia, aplicada pelo laser e pelo $L E D$, promove resultados satisfatórios para a diminuição da dor e do linfedema, assim como estimula os sistemas imunológico e linfático após a mastectomia. Os parâmetros empregados para o uso do laser variaram quanto ao comprimento de onda, entre 904 a $980 \mathrm{~nm}$ e dosagem 1,5 a $4,8 \mathrm{~J} / \mathrm{cm}^{2}$; já para o uso do $L E D$, variou apenas quanto ao o comprimento de onda, de 480 a 3.400 $\mathrm{nm}$. Nos estudos avaliados, a fototerapia mostrou ser uma terapêutica segura em pacientes oncológicos, sugerindo melhora sobre os aspectos da funcionalidade do indivíduo e da sua qualidade de vida.

\section{CONTRIBUIÇÕES}

Alessandra de Jesus Mota Rocha e Giovana Bergheme Franciscon De Lemos realizaram o planejamento do estudo, desde a escolha do tema, desenho de estudo e sua metodologia, avaliação dos dados coletados e interpretação, como também redigiu a versão final com o auxílio de Rachel Trinchão Schneiberg Kalid Ribeiro que contribuiu com a revisão crítica da versão final do estudo. Todas as autoras aprovaram a versão final do manuscrito.

\section{DECLARAÇÃO DE CONFLITO DE INTERESSES}

Nada a declarar

\section{FONTES DE FINANCIAMENTO}

Não há.

\section{REFERÊNCIAS}

1. Instituto Nacional de Câncer José Alencar Gomes da Silva. Estimativa 2018: incidência de câncer no Brasil [Internet]. Rio de Janeiro: INCA, 2017. [acesso 2019 abril 10]. Disponível em: http://www.inca.gov.br/ estimativa/2018/estimativa-2018.pdf.

2. Rietman JS, Dijkstra PU, Debreczeni R, et al. Impairments, disabilities and health related quality of life after treatment for breast cancer: a follow-up study 2.7 years after surgery. Disabil Rehabil. 2004;26(2):78-84. doi: https://doi.org/10.1080/09638280310001629642.

3. Cantu T, Walsh K, Pattani VP, et al. Conductive polymerbased nanoparticles for laser-mediated photothermal ablation of cancer: synthesis, characterization, and in vitro evaluation. Int J Nanomedicine. 2017;12:615-632. doi: https://doi.org/10.2147/IJN.S116583.

4. Batiston AP, Santiago SM. Fisioterapia e complicaçôes físico-funcionais após tratamento cirúrgico do câncer de mama. Fisioter Pesqui. 2005;12(3):30-34.

5. Góis MC, Trindade KMO, Cobucci RNO, et al. Prevalência das complicações pós-operatórias decorrentes da mastectomia radical modificada com linfadenectomia axilar. Rev Bras Mastologia. 2011;21(4):157-160.

6. Zhevago NA, Zimin AA, Glazanova TV, et al. Polychromatic light (480-3400 nm) similar to the terrestrial solar spectrum without its UV component in post-surgical immunorehabilitation of breast cancer patients. J Photochem Photobiol B. 2017;166:44-51. doi: https://doi.org/10.1016/j.jphotobiol.2016.10.040.

7. Banerjee SM, MacRobert AJ, Mosse CA, et al. Photodynamic therapy: inception to application in breast cancer. Breast. 2017;31:105-113. doi: https://doi. org/10.1016/j.breast.2016.09.016.

8. Robijns J, Censabella S, Bulens P, et al. The use of lowlevel light therapy in supportive care for patients with breast cancer: review of the literature. Lasers Med Sci. 2017;32(1):229-242. doi: https://doi.org/10.1007/ s10103-016-2056-y.

9. Li K, Xia L, Liu NF, et al. Far infrared ray (FIR) therapy: an effective and oncological safe treatment modality for breast cancer related lymphedema. J Photochem Photobiol B. 2017;172:95-101. doi: https://doi. org/10.1016/j.jphotobiol.2017.05.011.

10. Barolet D. Light-Emitting Diodes (LEDs) in dermatology. Semin Cutan Med Surg. 2008;27(4):227-238. doi: https://doi.org/10.1016/j.sder.2008.08.003.

11. Zhevago NA, Samoilova KA, Davydova NI, et al. [The efficacy of polychromatic visible and infrared radiation used for the postoperative immunological rehabilitation of patients with breast cancer]. Vopr Kurortol Fizioter Lech Fiz Kult [Internet]. 2012 [cited 2017 Dec 20];(4):23-32. Available from: http://www.embase.com/search/results.

12. Zimin AA, Samoilova KA, Zhevago NA. Proliferation of normal and tumor cells in presence of serum of patients with breast carcinoma after phototherapy with visible and near infrared light. Cell tissue boil. 2010;4(5):481-489. doi: https://doi.org/10.1134/S1990519X10050123.

13. Fife D, Rayhan DJ, Behnam S, et al. A randomized, controlled, double-blind study of light emitting diode photomodulation for the prevention of radiation dermatitis in patients with breast cancer. Dermatol Surg. 2010; 36(12):1921-1927. doi: https://doi.org/10.1111/ j.1524-4725.2010.01801.x 
14. Lau RWL, Cheing GLY. Managing postmastectomy lymphedema with low-level laser therapy. photomed laser surg. 2009;27(5):763-769. doi: https://doi.org/10.1089/ pho.2008.2330.

15. Lins RDAU, Lucena KCR, Granville-Garcia AF, et al. Efeitos bioestimulantes do laser de baixa potência no processo de reparo. An Bras Dermatol. 2010;85(6):849855.

16. Ahmed Omar MT, Abd-El-Gayed Ebid A, El Morsy AM. Treatment of post-mastectomy lymphedema with laser therapy: Double blind placebo control randomized study. J Surg Res. 2011;165(1):82-90. doi: https://doi. org/10.1016/j.jss.2010.03.050.

17. Storz MA, Gronwald B, Gottschling S, et al. Photobiomodulation therapy in breast cancer-related lymphedema: a randomized placebo-controlled trial. Photodermatol Photoimmunol Photomed. 2017;33(1):32-40. doi: https://doi.org/10.1111/ phpp. 12284. 